\title{
Effects of berberine on glucose-lipid metabolism, inflammatory factors and insulin resistance in patients with metabolic syndrome
}

\author{
CHANGFU CAO and MEIQING SU \\ Department of Pharmacy, Linyi Central Hospital, Linyi, Shandong 276400, P.R. China
}

Received June 13, 2018; Accepted January 31, 2019

DOI: $10.3892 /$ etm.2019.7295

\begin{abstract}
Effects of berberine on glucose-lipid metabolism, inflammatory factors and insulin resistance in patients with metabolic syndrome were investigated. Eighty patients with metabolic syndrome treated in Linyi Central Hospital from January 2017 to December 2017 were selected and divided into control group $(n=40)$ and observation group $(n=40)$. Patients in control group were treated with regular therapy using the Western medicine and drugs, while those in observation group, based on the treatment in control group, were treated with berberine. Changes in relevant indexes to blood glucose and lipid metabolisms and inflammatory factors were compared between the two groups. The correlation of inflammatory factor with fasting blood glucose, insulin resistance, triglyceride and total cholesterol was analyzed. At 1 month after treatment, levels of fasting blood glucose, $2 \mathrm{~h}$ postprandial blood glucose, insulin resistance index and blood lipid indexes in both groups were lower than those at 1 week after treatment $(\mathrm{P}<0.05)$. At 1 month after treatment, levels of fasting blood glucose, $2 \mathrm{~h}$ postprandial blood glucose, insulin resistance index and blood lipid indexes in observation group were significantly lower than those in control group during the same period $(\mathrm{P}<0.05)$. Moreover, levels of high-sensitivity $\mathrm{C}$-reactive protein (hs-CRP), interleukin-6 (IL-6) and tumor necrosis factor- $\alpha(\mathrm{TNF}-\alpha)$ in both groups at 1 month after treatment were lower than those at 1 week after treatment $(\mathrm{P}<0.05)$, and they were lower in observation group at 1 month after treatment than those in control group during the same period $(\mathrm{P}<0.05)$. Finally, hs-CRP was positively correlated with fasting blood glucose, insulin resistance, total cholesterol
\end{abstract}

Correspondence to: Dr Changfu Cao, Department of Pharmacy, Linyi Central Hospital, 17 Jiankang Road, Linyi, Shandong 276400, P.R. China

E-mail: c9011168@163.com

Key words: berberine, metabolic syndrome, blood glucose metabolism, blood lipid metabolism, inflammatory factors, insulin resistance and triglyceride. The combined application of berberine in patients with metabolic syndrome can effectively regulate blood glucose and blood lipid of patients, alleviate insulin resistance and reduce the level of inflammatory response in the body.

\section{Introduction}

Metabolic syndrome mainly refers to a group of pathophysiological changes based on insulin resistance (1), the major clinical manifestations are central obesity, increase in blood glucose, increase in blood lipid and increase in blood pressure, seriously affecting the physical health of patients. The above clinical manifestations of metabolic syndrome, as a metabolic dysfunction-related disease (2), have certain common risk factors, which are in line with the "concept of holism, homotherapy for heteropathy' in the traditional Chinese medicine. It is of important significance to effectively intervene in patients with cardiovascular diseases, such as hypertension, and endocrine diseases (like type 2 diabetes mellitus) (3), alleviate or avoid the occurrence of insulin resistance and make full use of the concept of "preventive treatment of disease', namely 'prevention before disease onset, prevention of disease from exacerbating', in the traditional Chinese medicine, thereby increasing the therapeutic effect on metabolic syndrome and improving the prognosis of patients (4).

Berberine, also known as Berberine hydrochloride in clinic, is the isoquinoline alkaloid, an active ingredient extracted from Chinese herbal medicines, such as Coptis chinensis and Phellodendron amurense, which has dominant advantages such as reducing blood glucose, and regulating blood lipid and vascular endothelial cells (5). In recent years, berberine has been widely used in the treatment of type 2 diabetes mellitus, hypertension and hyperlipidemia (6). With the deepening of fundamental research on berberine, it has been confirmed that the main mechanisms of berberine in reducing blood glucose and blood pressure and regulating blood lipid are promotion of insulin secretion and improvement of the body's insulin resistance (7). To better investigate the clinical value of berberine in the treatment of metabolic syndrome, this study was performed from the perspectives of blood glucose, blood lipid, insulin resistance and inflammatory factor levels. 
Table I. Comparison of general data and related indexes between the two groups (mean \pm SD).

\begin{tabular}{lccccc}
\hline Group & $\begin{array}{c}\text { Sex } \\
\text { (male/female) }\end{array}$ & $\begin{array}{c}\text { Age } \\
\text { (years) }\end{array}$ & $\begin{array}{c}\text { Fasting blood } \\
\text { glucose (mmol/l) }\end{array}$ & $\begin{array}{c}\text { 2 h postprandial } \\
\text { blood glucose (mmol/l) }\end{array}$ & $\begin{array}{c}\text { Insulin } \\
\text { resistance }\end{array}$ \\
\hline Observation group & $20 / 20$ & $65.6 \pm 1.8$ & $10.5 \pm 0.6$ & $13.5 \pm 1.3$ & $1.5 \pm 0.1$ \\
Control group & $20 / 20$ & $65.5 \pm 1.8$ & $10.6 \pm 0.6$ & $13.6 \pm 1.3$ & $1.5 \pm 0.1$ \\
$\chi^{2}$ or t value & $<0.001$ & 0.248 & 0.745 & 0.344 & $<0.001$ \\
P-value & $>0.05$ & 0.804 & 0.458 & 0.732 & $>0.05$ \\
\hline
\end{tabular}

Continued

\begin{tabular}{lccccc}
\hline Group & $\begin{array}{c}\text { Triglyceride } \\
(\mathrm{mmol} / \mathrm{l})\end{array}$ & $\begin{array}{c}\text { Total } \\
\text { cholesterol } \\
(\mathrm{mmol} / \mathrm{l})\end{array}$ & $\begin{array}{c}\text { Interleukin-6 } \\
(\mathrm{IL}-6)(\mathrm{ng} / \mathrm{l})\end{array}$ & $\begin{array}{c}\text { Tumor necrosis } \\
\text { factor- } \alpha \\
(\text { TNF- } \alpha)(\mathrm{ng} / \mathrm{l})\end{array}$ & $\begin{array}{c}\text { High-sensitivity } \\
\text { C-reactive protein } \\
(\mathrm{hs}-\mathrm{CRP})(\mathrm{ml} / \mathrm{l})\end{array}$ \\
\hline Observation group & $2.53 \pm 0.13$ & $6.11 \pm 0.09$ & $0.69 \pm 0.05$ & $253.1 \pm 2.1$ & $25.6 \pm 1.3$ \\
Control group & $2.55 \pm 0.13$ & $6.12 \pm 0.10$ & $0.70 \pm 0.05$ & $253.6 \pm 2.0$ & $25.7 \pm 1.4$ \\
$\chi^{2}$ or t value & 0.688 & 0.470 & 0.894 & 1.090 & 0.331 \\
P-value & 0.493 & 0.640 & 0.374 & 0.279 & 0.742 \\
\hline
\end{tabular}

Table II. Changes in related indexes to blood glucose and lipid metabolisms in both groups at 1 week and 1 month after treatment $($ mean $\pm \mathrm{SD})$.

\begin{tabular}{|c|c|c|c|c|c|c|}
\hline Group & Treatment & $\begin{array}{c}\text { Fasting blood } \\
\text { glucose } \\
(\mathrm{mmol} / \mathrm{l})\end{array}$ & $\begin{array}{l}2 \mathrm{~h} \text { postprandial } \\
\text { blood glucose } \\
(\mathrm{mmol} / \mathrm{l})\end{array}$ & $\begin{array}{l}\text { Insulin } \\
\text { resistance }\end{array}$ & $\begin{array}{l}\text { Triglyceride } \\
(\mathrm{mmol} / \mathrm{l})\end{array}$ & $\begin{array}{l}\text { Total cholesterol } \\
(\mathrm{mmol} / \mathrm{l})\end{array}$ \\
\hline \multirow[t]{2}{*}{ Observation group } & 1 week after treatment & $7.9 \pm 0.3$ & $9.9 \pm 0.5$ & $1.3 \pm 0.1$ & $2.12 \pm 0.08$ & $5.39 \pm 0.15$ \\
\hline & 1 month after treatment & $5.6 \pm 0.2^{\mathrm{a}, \mathrm{b}}$ & $7.5 \pm 0.3^{\mathrm{a}, \mathrm{b}}$ & $1.1 \pm 0.11^{\mathrm{a}, \mathrm{b}}$ & $1.56 \pm 0.07^{\mathrm{a}, \mathrm{b}}$ & $3.69 \pm 0.08^{\mathrm{a}, \mathrm{b}}$ \\
\hline \multirow[t]{8}{*}{ Control group } & 1 week after treatment & $8.0 \pm 0.4$ & $10.0 \pm 0.5$ & $1.4 \pm 0.1$ & $2.13 \pm 0.09$ & $5.40 \pm 0.16$ \\
\hline & 1 month after treatment & $6.5 \pm 0.3^{\mathrm{a}}$ & $8.5 \pm 0.61^{\mathrm{a}}$ & $1.3 \pm 0.11^{\mathrm{a}}$ & $1.96 \pm 0.061^{\mathrm{a}}$ & $5.23 \pm 0.101^{\mathrm{a}}$ \\
\hline & $t_{1}$ & 40.345 & 26.032 & 8.944 & 33.318 & 62.129 \\
\hline & $p_{1}$ & $<0.001$ & $<0.001$ & $<0.001$ & $<0.001$ & $<0.001$ \\
\hline & $t_{2}$ & 18.974 & 12.147 & 4.472 & 9.940 & 5.698 \\
\hline & $p_{2}$ & $<0.001$ & $<0.001$ & $<0.001$ & $<0.001$ & $<0.001$ \\
\hline & $t_{3}$ & 15.787 & 9.428 & 8.944 & 27.440 & 76.055 \\
\hline & $p_{3}$ & $<0.001$ & $<0.001$ & $<0.001$ & $<0.001$ & $<0.001$ \\
\hline
\end{tabular}

${ }^{\mathrm{a}} \mathrm{P}<0.05$ vs. observation group and control group at 1 week after treatment; ${ }^{\mathrm{b}} \mathrm{P}<0.05$ vs. control group at 1 week after treatment. $t_{l}$, the results of comparison in observation group between 1 month after treatment and 1 week after treatment. $t_{2}$, the results of comparison in observation group between 1 month after treatment and 1 week after treatment. $t_{3}$, the results of comparison between observation group and control group at 1 month after treatment.

\section{Patients and methods}

Patient data. A total of 80 patients with metabolic syndrome treated in Linyi Central Hospital (Linyi, China) from January 2017 to December 2017 were selected. All patients met the diagnostic criteria of the Chinese Medical Association (8) for type 2 diabetes mellitus, hyperlipidemia and hypertension. Before enrollment, patients signed an informed consent, and this study was approved by the Ethics Committee of Linyi Central Hospital. Patients enrolled were aged 60-80 years, and they were physically healthy in the past. Exclusion criteria: i) Patients complicated with other endocrine system diseases, mental diseases, malignant tumor or chronic obstructive pulmonary disease, ii) patients who were illiterate, allergic to drugs applied or could not pay the medical expenses. Patients were divided into two groups with 40 cases in each group using the random number method. There were no statistically significant differences in comparisons of general data and related indexes between the two groups $(\mathrm{P}>0.05)$ (Table I).

Methods. Patients in control group were treated with regular therapy using the Western medicine and drugs strictly in accordance with the treatment guidelines of metabolic syndrome of the Chinese Medical Association. First of all, the weight of 
Table III. Changes in inflammatory factors in both groups at 1 week and 1 month after treatment (mean \pm SD).

\begin{tabular}{|c|c|c|c|c|}
\hline Group & Treatment & hs-CRP (ml/l) & IL-6 (ng/l) & TNF- $\alpha(n g / l)$ \\
\hline \multirow[t]{2}{*}{ Observation group } & 1 week after treatment & $12.3 \pm 0.5$ & $0.59 \pm 0.06$ & $136.8 \pm 11.1$ \\
\hline & 1 month after treatment & $8.5 \pm 0.3^{\mathrm{a}, \mathrm{b}}$ & $0.43 \pm 0.04^{\mathrm{a}, \mathrm{b}}$ & $83.2 \pm 7.6^{\mathrm{a}, \mathrm{b}}$ \\
\hline \multirow[t]{8}{*}{ Control group } & 1 week after treatment & $14.6 \pm 0.6$ & $0.68 \pm 0.06$ & $146.5 \pm 11.3$ \\
\hline & 1 month after treatment & $11.6 \pm 0.4^{\mathrm{a}}$ & $0.51 \pm 0.05^{\mathrm{a}}$ & $108.9 \pm 8.3^{\mathrm{a}}$ \\
\hline & $t_{1}$ & 41.217 & 14.033 & 25.199 \\
\hline & $p_{1}$ & $<0.001$ & $<0.001$ & $<0.001$ \\
\hline & $t_{2}$ & 26.312 & 13.766 & 16.961 \\
\hline & $p_{2}$ & $<0.001$ & $<0.001$ & $<0.001$ \\
\hline & $t_{3}$ & 39.212 & 7.902 & 14.443 \\
\hline & $p_{3}$ & $<0.001$ & $<0.001$ & $<0.001$ \\
\hline
\end{tabular}

${ }^{\mathrm{a}} \mathrm{P}<0.05$ vs. observation group and control group at 1 week after treatment; ${ }^{\mathrm{b}} \mathrm{P}<0.05$ vs. control group at 1 week after treatment. $t_{l}$, the results of comparison in observation group between 1 month after treatment and 1 week after treatment. $t_{2}$, the results of comparison in observation group between 1 month after treatment and 1 week after treatment. $t_{3}$, the results of comparison between observation group and control group at 1 month after treatment.

patients was reduced, the diet adjustment was strengthened, and the body mass index $\leq 28$. Patients exercised properly according to the body's tolerance, and it was recommended that they take part in light-moderate physical activity every day for half an hour. In addition, the insulin resistance was reduced, in other words, the blood glucose-regulating drugs, such as metformin and insulin sensitizing drug thiazolidinedione, were applied while diet and exercise interventions were performed. At the same time, the intervention in hyperlipidemia was also performed, and it was advised that fibrates and statins be applied. Finally, the patient's blood pressure was adjusted and controlled within 130/80 $\mathrm{mmHg}$. In terms of antihypertensive drugs, angiotensin-converting enzyme inhibitor (ACEI) and/or angiotensin II receptor antagonist (ARB) were preferred choices. Patients in observation group, based on the treatment in control group, were treated with berberine (Jiangxi Sinopharm Co., Ltd., Jiangxi, China, NMPN Z36020766) 3 times a day (4 tablets/time).

Observation indexes. All patients were followed up for 1 month. Changes in relevant indexes to blood glucose and lipid metabolisms and inflammatory factors were compared between the two groups at 1 week and 1 month after treatment. The correlations of inflammatory factor hs-CRP with fasting blood glucose, insulin resistance, triglyceride and total cholesterol were analyzed.

Evaluation criteria. Related detection indexes to blood glucose included fasting blood glucose (3.9-6.1 mmol/l), $2 \mathrm{~h}$ postprandial blood glucose ( $\leq 7.8 \mathrm{mmol} / \mathrm{l})$ and homeostasis model assessment - insulin resistance (HOMA-IR) [reference value: 1, calculation formula: fasting blood glucose $(\mathrm{mmol} / \mathrm{l}) \mathrm{x}$ fasting insulin (mU/1)]. Related indexes to blood lipid included triglyceride (0.56-1.71 mmol/l) and total cholesterol (2.83-5.17 mmol/l). Inflammation-related factors included hs-CRP ( $<10 \mathrm{ml} / \mathrm{l})$, IL-6 (0.37-0.46 ng/l) and TNF- $\alpha$ (5-100 ng/l).

Statistical analysis. SPSS 13.0 software (SPSS Inc., Chicago, IL, USA) was used for statistical analysis. Measurement data are presented as mean \pm standard deviation (mean $\pm \mathrm{SD}$ ). Student's t-test was used for the comparison of related indexes to blood glucose and lipid metabolisms between the two groups at different observation points, the Chi-square test $\left(\chi^{2}\right)$ was used for the comparison of adverse reactions between the two groups, and correlations of hs-CRP with fasting blood glucose, insulin resistance, total cholesterol and triglyceride were analyzed using the Pearson's correlation coefficient method. The procedure was repeated 3 times. $\mathrm{P}<0.05$ was considered to indicate a statistically significant difference.

\section{Results}

Changes in related indexes to blood glucose and lipid metabolisms in both groups at 1 week and 1 month after treatment. At 1 month after treatment, levels of fasting blood glucose, $2 \mathrm{~h}$ postprandial blood glucose and insulin resistance index in both groups were lower than those at 1 week after treatment $(\mathrm{P}<0.05)$, and levels of blood lipid indexes (triglyceride and total cholesterol) were also lower than those at 1 week after treatment $(\mathrm{P}<0.05)$. At 1 month after treatment, levels of fasting blood glucose, $2 \mathrm{~h}$ postprandial blood glucose and insulin resistance index in observation group were significantly decreased compared with those in control group during the same period $(\mathrm{P}<0.05)$, and levels of blood lipid indexes (triglyceride and total cholesterol) were also lowered compared with those in control group during the same period $(\mathrm{P}<0.05)$ (Table II).

Changes in inflammatory factors in both groups at 1 week and 1 month after treatment. Levels of hs-CRP, IL- 6 and TNF- $\alpha$ in both groups at 1 month after treatment were lower than those at 1 week after treatment $(\mathrm{P}<0.05)$, and they were lower in observation group at 1 month after treatment than those in control group during the same period $(\mathrm{P}<0.05)$ (Table III).

Correlation analysis of inflammatory factor $h s-C R P$ with fasting blood glucose. There was a positive correlation 


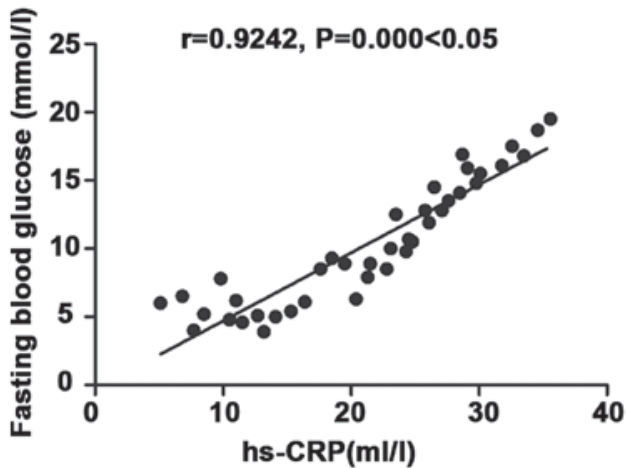

Figure 1. Correlation analysis of inflammatory factor hs-CRP with fasting blood glucose. There is a positive correlation between inflammatory factor hs-CRP and fasting blood glucose $(r=0.9242, \mathrm{P}<0.05)$.

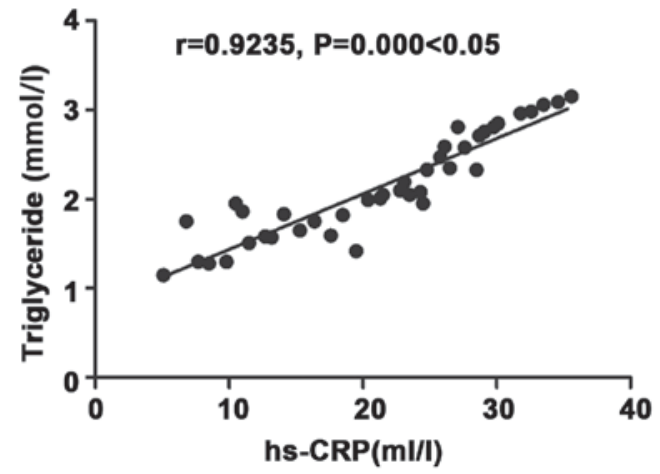

Figure 3. Correlation analysis of inflammatory factor hs-CRP with triglyceride. There is a positive correlation between inflammatory factor hs-CRP and triglyceride $(\mathrm{r}=0.9235, \mathrm{P}<0.05)$.

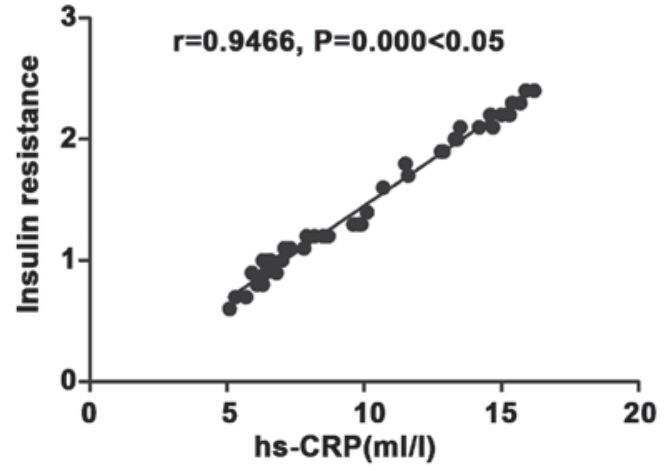

Figure 2. Correlation analysis of inflammatory factor hs-CRP with insulin resistance. There is a positive correlation between inflammatory factor hs-CRP and insulin resistance $(\mathrm{r}=0.9929, \mathrm{P}<0.05)$.

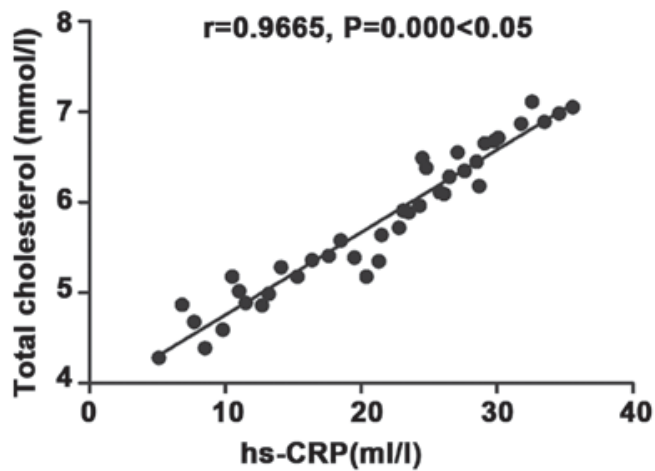

Figure 4. Correlation analysis of inflammatory factor hs-CRP with total cholesterol. There is a positive correlation between inflammatory factor hs-CRP and total cholesterol $(\mathrm{r}=0.9665, \mathrm{P}<0.05)$.

Table IV. Comparison of adverse reactions between the two groups.

\begin{tabular}{lccccc}
\hline Group & Ketoacidosis & $\begin{array}{c}\text { Hyperglycemic } \\
\text { coma }\end{array}$ & Hypoglycemia & $\begin{array}{c}\text { Nausea and } \\
\text { vomiting }\end{array}$ & $\begin{array}{c}\text { Overall incidence } \\
\text { rate }\end{array}$ \\
\hline $\begin{array}{l}\text { Observation group } \\
\text { Control group }\end{array}$ & 1 & 1 & 1 & 1 & $4(10.0 \%)$ \\
$\chi^{2}$ value & 1 & 2 & 1 & 0 & $4(10.0 \%)$ \\
P-value & & & & $<0.001$ \\
\hline
\end{tabular}

between inflammatory factor hs-CRP and fasting blood glucose $(r=0.9242, \mathrm{P}<0.05)$ (Fig. 1).

Correlation analysis of inflammatory factor hs-CRP with insulin resistance. There was a positive correlation between inflammatory factor hs-CRP and insulin resistance ( $\mathrm{r}=0.9929$, $\mathrm{P}<0.05)$ (Fig. 2).

Correlation analysis of inflammatory factor hs-CRP with triglyceride. There was a positive correlation between inflammatory factor hs-CRP and triglyceride $(\mathrm{r}=0.9235$, $\mathrm{P}<0.05)$ (Fig. 3).

Correlation analysis of inflammatory factor hs-CRP with total cholesterol. There was a positive correlation between inflammatory factor hs-CRP and total cholesterol ( $\mathrm{r}=0.9665$, $\mathrm{P}<0.05$ ) (Fig. 4).

Comparison of adverse reactions between the two groups. There was no statistically significant difference in the overall incidence rate of adverse reactions, such as ketoacidosis, hyperglycemic coma, hypoglycemia and nausea and vomiting, between the two groups $(\mathrm{P}>0.05)$ (Table IV).

\section{Discussion}

Metabolic syndrome is a group of clinical syndromes determined by heredity, environment, living habits and other factors, whose main mechanism is insulin resistance (9). Patients have symptoms including central obesity, atherosclerosis, 
rise of blood lipid, pathoglycemia and elevation of blood pressure, which may be accompanied by microalbuminuria, hyperuricemia and long-term rise of chronic inflammatory cytokines (10). Currently, most scholars consider that insulin resistance is the most crucial independent risk factor and central link that lead to metabolic syndrome (11). Treatment for metabolic syndrome is based on improvement of patients' way of life, regulation of eating habits, exercise training and loss of weight, combined with drug therapy of reducing blood lipid and regulating blood pressure and blood glucose (12). Berberine can regulate various metabolic disorders of metabolic syndrome, which has advantages of wide medicinal herbs resources, low price, smaller adverse reactions, and is also safe and convenient (13).

In this study, patients with metabolic syndrome in control group were given regular Western medicine treatment strictly following guideline requirements, while those in observation group received berberine treatment on the basis of that in control group. By analyzing changes of related indexes to blood glucose and lipid metabolisms in the groups at 1 week and 1 month after treatment, it was found that related indexes to blood glucose and lipid in both groups were improved at 1 month after treatment, but levels of fasting blood glucose, $2 \mathrm{~h}$ postprandial blood glucose and insulin resistance index in observation group were significantly lower than those in control group at 1 month after treatment, and levels of blood lipid indexes (triglyceride and total cholesterol) in observation group were lower than those in control group at 1 month after treatment, indicating that combined use of berberine can regulate blood glucose and blood lipid levels more effectively and lighten insulin resistance. By exploring changes in relevant indexes of inflammatory factors in both groups at 1 week and 1 month after treatment, it was found that hs-CRP, IL-6 and TNF- $\alpha$ levels in both groups were also lower than those at 1 week after treatment, but hs-CRP, IL- 6 and TNF- $\alpha$ levels in observation group were all lower than those in control group at 1 month after treatment, indicating that combined use of berberine tablets is of important significance for reducing inflammatory reaction in patients with metabolic syndrome. From the correlation research on inflammatory response factor hs-CRP with fasting blood glucose, insulin resistance, total cholesterol and triglyceride, it was revealed that hs-CRP was positively related to fasting blood glucose, insulin resistance, total cholesterol and triglyceride, which further indicates that there is chronic inflammatory response in the body of patients with metabolic syndrome and the severity degree of inflammatory response is related to blood glucose and blood lipid metabolism. Chronic inflammatory response may also lead to increase of insulin resistance in the body and further worsen the disease condition. Besides, combined use of berberine tablets did not increase the incidence of adverse reactions of treatment, so combined use of berberine tablets is of high safety.

In this study, combined use of berberine could effectively improve activity of adenosine monophosphate-activated protein kinase (AMPK) of islet cells, thus promoting activation of cyclic adenosine monophosphate (CAMP) signal pathway (14) and active secretion of insulin in the body. Moreover, berberine can also stimulate free fatty acid to induce secretion of insulin (15). Berberine improves physiological stimulation of glucose via cascade reaction of insulin-like growth factor-1 (IGF-1), thus inducing secretion of insulin in the body, reducing insulin resistance, and improving sensitivity of liver, muscle tissues and fat to insulin (16). Berberine can improve the activity and promote the proliferation of insulin $\beta$ cells (17). Therefore, the combined use of berberine in observation group could better control fasting blood glucose and $2 \mathrm{~h}$ postprandial plasma glucose and reduce insulin resistance in the body. Berberine inhibits synthesis and secretion of proteolipid protein and activity of peroxisome by enhancing low density lipoprotein receptor level and promoting adenylate-phosphoric acidactivated protein kinase activity, thus regulating blood lipid and inhibiting proliferation and differentiation of adipocytes, so as to achieve the objective of reducing free fatty acid in serum $(18,19)$. Consequently, triglyceride and total cholesterol decreased significantly after combined use of berberine in observation group. In addition, berberine can also evidently decrease levels of hs-CRP, IL-6, TNF- $\alpha$ and other inflammatory cytokines in the body (20), improve calcium overload and ischemia reperfusion injury and provide anti-oxidative capacity (21).

In conclusion, combined use of berberine for patients with metabolic syndrome can effectively regulate blood glucose and lipid, lighten insulin resistance in the body and reduce inflammatory response level.

\section{Acknowledgements}

Not applicable.

\section{Funding}

No funding was received.

\section{Availability of data and materials}

The datasets used and/or analyzed during the current study are available from the corresponding author on reasonable request.

\section{Authors' contributions}

CC wrote the manuscript and collected the general data. CC and MS analyzed the relevant indexes to blood glucose and lipid metabolisms and inflammatory factors. Both authors read and approved the final manuscript.

\section{Ethics approval and consent to participate}

The study was approved by the Ethics Committee of Linyi Central Hospital (Linyi, China) and informed consents were signed by the patients or the guardians.

\section{Patient consent for publication}

Not applicable.

\section{Competing interests}

The authors declare that they have no competing interests. 


\section{References}

1. Saleem F and Rizvi SW: New therapeutic approaches in obesity and metabolic syndrome associated with polycystic ovary syndrome. Cureus 9: e1844, 2017.

2. Marchitto N, Sindona F, Fabrizio A, Mauti M, Andreozzi S, Dalmaso S and Raimondi G: Effect of new nutraceutical formulation with policosanol, berberine, red yeast rice, cassia nomame, astaxantine and Q10 coenzyme in patients with low-moderate dyslipidemia associated with intolerance to statins and metabolic syndrome. Minerva Cardioangiol 66: 124-125, 2018.

3. Liu Q, Zhu L, Cheng C, Hu YY and Feng Q: Natural active compounds from plant food and chinese herbal medicine for nonalcoholic fatty liver disease. Curr Pharm Des 23: 5136-5162, 2017.

4. Dahlberg CJ, Ou JJ, Babish JG, Lamb JJ, Eliason S, Brabazon H, Gao W, Kaadige MR and Tripp ML: A 13-week low glycemic load diet and lifestyle modification program combining low glycemic load protein shakes and targeted nutraceuticals improved weight loss and cardio-metabolic risk factors. Can J Physiol Pharmacol 95: 1414-1425, 2017.

5. Sirtori CR, Pavanello C, Calabresi L and Ruscica M: Nutraceutical approaches to metabolic syndrome. Ann Med 49: 678-697, 2017.

6. Guarino G, Strollo F, Carbone L, Della Corte T, Letizia M, Marino $\mathrm{G}$ and Gentile S: Bioimpedance analysis, metabolic effects and safety of the association Berberis aristata/Bilybum marianum: A 52-week double-blind, placebo-controlled study in obese patients with type 2 diabetes. J Biol Regul Homeost Agents 31: 495-502, 2017.

7. Tabeshpour J, Imenshahidi M and Hosseinzadeh H: A review of the effects of Berberis vulgaris and its major component, berberine, in metabolic syndrome. Iran J Basic Med Sci 20: 557-568, 2017.

8. Ong M, Peng J, Jin X and Qu X: Chinese herbal medicine for the optimal management of polycystic ovary syndrome. Am J Chin Med 45: 405-422, 2017.

9. Lu YH, Lu JM, Wang SY, Li CL, Liu LS, Zheng RP, Tian H, Wang XL, Yang LJ, Zhang YQ and Pan CY: Comparison of the diagnostic criteria of metabolic syndrome by International Diabetes Federation and that by Chinese Medical Association Diabetes Branch. Zhonghua Yi Xue Za Zhi 86: 386-389, 2006 (In Chinese).

10. Zhao L, Cang Z, Sun H, Nie X, Wang N and Lu Y: Berberine improves glucogenesis and lipid metabolism in nonalcoholic fatty liver disease. BMC Endocr Disord 17: 13, 2017.

11. Choi YJ, Lee KY, Jung SH, Kim HS, Shim G, Kim MG, Oh YK, Oh SH, Jun DW and Lee BH: Activation of AMPK by berberine induces hepatic lipid accumulation by upregulation of fatty acid translocase CD36 in mice. Toxicol Appl Pharmacol 316: 74-82, 2017.
12. Chow YL, Sogame M and Sato F: 13-Methylberberine, a berberine analogue with stronger anti-adipogenic effects on mouse 3T3-L1 cells. Sci Rep 6: 38129, 2016.

13. He Q, Mei D, Sha S, Fan S, Wang L and Dong M: ERK-dependent mTOR pathway is involved in berberine-induced autophagy in hepatic steatosis. J Mol Endocrinol 57: 251-260, 2016.

14. Li M, Shu X, Xu H, Zhang C, Yang L, Zhang L and Ji G: Integrative analysis of metabolome and gut microbiota in dietinduced hyperlipidemic rats treated with berberine compounds. J Transl Med 14: 237, 2016.

15. Millán J, Cicero AF, Torres F and Anguera A: Effects of a nutraceutical combination containing berberine (BRB), policosanol, and red yeast rice (RYR), on lipid profile in hypercholesterolemic patients: A meta-analysis of randomised controlled trials. Clin Investig Arterioscler 28: 178-187, 2016.

16. Martínez-Abundis E, Méndez-Del Villar M, Pérez-Rubio KG, Zuñiga LY, Cortez-Navarrete M, Ramírez-Rodriguez A and González-Ortiz M: Novel nutraceutic therapies for the treatment of metabolic syndrome. World J Diabetes 7: 142-152, 2016.

17. Caliceti C, Franco P, Spinozzi S, Roda A and Cicero AF: Berberine: New insights from pharmacological aspects to clinical evidences in the management of metabolic disorders. Curr Med Chem 23: 1460-1476, 2016.

18. Patel S: Functional food red yeast rice (RYR) for metabolic syndrome amelioration: A review on pros and cons. World J Microbiol Biotechnol 32: 87, 2016.

19. Geng FH, Li GH, Zhang X, Zhang P, Dong MQ,Zhao ZJ, Zhang Y, Dong L and Gao F: Berberine improves mesenteric artery insulin sensitivity through up-regulating insulin receptor-mediated signalling in diabetic rats. Br J Pharmacol 173: 1569-1579, 2016.

20. Oikawa N, Nobushi Y, Wada T, Sonoda K, Okazaki Y, Tsutsumi S, Park YK, Kurokawa M, Shimba S and Yasukawa K: Inhibitory effects of compounds isolated from the dried branches and leaves of murta (Myrceugenia euosma) on lipid accumulation in 3T3-L1 cells. J Nat Med 70: 502-509, 2016.

21. Cicero AF and Colletti A: Role of phytochemicals in the management of metabolic syndrome. Phytomedicine 23: 1134-1144, 2016

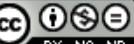

This work is licensed under a Creative Commons Attribution-NonCommercial-NoDerivatives 4.0 International (CC BY-NC-ND 4.0) License. 